\title{
Simulations with a radiation model and comparisons with LBA data sets
}

\author{
Sergio H. Franchito, E. C. Moraes, and V. Brahmananda Rao \\ Centro de Previsão de Tempo e Estudos Climáticos (CPTEC), Instituto Nacional de Pesquisas Espaciais (INPE), São José dos \\ Campos, Brazil \\ Received 4 October 2001; revised 18 April 2002; accepted 9 May 2002; published 31 October 2002.
}

[1] The Large-Scale Biosphere-Atmosphere Experiment in Amazonia (LBA) data are used to estimate and validate infrared and solar radiation models calculations of Chou and Suarez [1994, 1999]. The models are tested for two contrasting vegetation regions. forest and grassland. Observed data of several days and different times of a day collected in the two sites are used to test the models. The results show that the model simulations in general agree well with the observations for both the forest and grassland cases. The mean errors are around the same order or lower than the instrument errors, except in the case of the reflected solar radiation. The radiation fluxes are strongly correlated with the observed data, significant at $99 \%$ confidence level, except in the case of the downward longwave radiation. The use of the Bonferrone technique confirmed the information given by the correlation coefficient calculations. INDEX TERMS: 3359 Meteorology and Atmospheric Dynamics: Radiative processes; 3322 Meteorology and Atmospheric Dynamics: Land/atmosphere interactions; 0360 Atmospheric Composition and Structure: Transmission and scattering of radiation; 0315 Atmospheric Composition and Structure: Biosphere/atmosphere interactions; KEYWORDS: radiation model, radiative fluxes in LBA data set, simulation of radiative fluxes in Rondonia

Citation: Franchito, S. H., E. C. Moraes, and V. B. Rao, Simulations with a radiation model and comparisons with LBA data sets, J. Geophys. Res., 107(D20), 8092, doi:10.1029/2001JD001356, 2002.

\section{Introduction}

[2] The heating by incoming shortwave solar radiation and the cooling by longwave radiation to space constitute the fundamental processes driving the earth's climate system. The large-scale dynamical system in the atmosphere is driven basically by differences between the net radiation at the equator and the poles. Therefore, any attempt to simulate the climate system must be accompanied by an adequate representation of the radiation processes. The objective of any parameterization of atmospheric radiation in a climatic model is to provide a simple, accurate and fast method of calculating the net radiation heating profile. These calculations must supply the total radiative flux at the surface in order to obtain the surface energy balance, and the vertical and horizontal radiative heating and cooling rates of an atmospheric volume. Chou et al. [1991] and Chou [1992] developed a fast and efficient parameterization schemes for the thermal infrared radiation and solar radiation, respectively. The scheme includes the combined effects of absorption and scattering due to the major gases (water vapor, carbon dioxide, $\mathrm{CO}_{2}$, and ozone, $\mathrm{O}_{3}$ ) and most of the minor trace gases (nitrous oxide, $\mathrm{N}_{2} \mathrm{O}$, methane, $\mathrm{CH}_{4}$, and chlorofluorcarbons, CFCs) together with clouds and aerosols. These parameterizations were improved in a series of subsequent papers [Chou et al., 1995; Chou and Lee, 1996; Chou and Zhao, 1997; Chou and Suarez, 1994,

Copyright 2002 by the American Geophysical Union. 0148-0227/02/2001JD001356\$09.00
1999]. The solar radiation model was validated using data from the TOGA-COARE (The Tropical Ocean and Global Atmosphere Coupled Ocean-Atmosphere Response Experiment) [Chou and Zhao, 1997]. Tests with the infrared radiation model and comparisons with results of GCMs were carried out by Chou and Suarez [1994]. However, it would be necessary to further validate the radiation models with other independent data sets. Presently, surface radiation data are available from the LBA (Large-Scale BiosphereAtmosphere Experiment in Amazonia). The LBA is an international multidisciplinary research initiative led by Brazil in order to obtain new knowledge needed to understand the climatological, ecological, biogeochemical and hydrological function of Amazonia and the interaction between Amazonia and Earth system. The LBA first intensive field campaign took place during the rainy season from January to March 1999. The objective of the present study is to test the radiation models developed by Chou and collaborators for two different scenarios in Amazonia. forest and grassland. For this purpose, radiation and radiosonde data collected during the LBA are used.

\section{Radiation Model}

[3] We use the thermal infrared and solar radiation parameterization schemes developed by Chou and Suarez [1994] and Chou and Suarez [1999], respectively. These radiation models take into account a horizontally homogeneous atmosphere. Chou and Suarez's [1994] original model assumes a blackbody infrared emissivity. In a recent version 
Table 1a. Equipment Used for Collecting Radiation Data During WETAMC/LBA Campaign (6 to 20 February) in the Forest Sites

\begin{tabular}{|c|c|c|c|c|}
\hline Equipment & Measurement & Sensibility & Units & Models \\
\hline Pyronometer & $\begin{array}{l}\text { incident and reflected } \\
\text { shortwave radiation }\end{array}$ & $\begin{array}{l} \pm 0.5 \% \text { in } 293 \mathrm{~K} \text { and } \\
500 \mathrm{Wm}^{-2}\end{array}$ & $\mathrm{~W} \mathrm{m^{-2 }}$ & $\begin{array}{l}\text { Solarimeter CM11 Kipp and } \\
\text { Zonen (Delft, Netherlands) }\end{array}$ \\
\hline Net radiometer & net radiation & $< \pm 5 \%$ & $\mathrm{~W} \mathrm{~m} \mathrm{~m}^{-2}$ & REBS (Seattle, Washington) \\
\hline Sensor quantum & PAR & $\begin{array}{l}0.2 \mathrm{~kW}-2 \mathrm{mV}-1 \text { and } \\
\text { maximum error of } \pm 5 \%\end{array}$ & 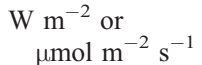 & $\begin{array}{l}\text { Sensor quantum LI190SB - } \\
\text { L150 Licor (Nebraska) }\end{array}$ \\
\hline Pyronometer $(\downarrow)(\uparrow)$ & net shortwave radiation & $\pm 10 \%$ in $(233$ and $343 \mathrm{~K})$ & $\mathrm{W} \mathrm{m}^{-2}$ & $\begin{array}{l}\text { CM3 Kipp and Zonen (Delft, } \\
\text { Netherlands) }\end{array}$ \\
\hline Pyrgeometer $(\downarrow)(\uparrow)$ & net longwave radiation & $\pm 10 \%$ in $(233$ and $343 \mathrm{~K})$ & $\mathrm{W} \mathrm{m} \mathrm{m}^{-2}$ & $\begin{array}{l}\text { CG3 Kipp and Zonen (Delft, } \\
\text { Netherlands) }\end{array}$ \\
\hline
\end{tabular}

of the model [Chou and Suarez, 1999] the surface was treated as nonblack, so they consider the surface emissivity in 10 spectral bands. In the present study, we use this new version of the model. These schemes use several broadband parameterization schemes for longwave and shortwave radiation to produce a computationally fast and accurate representation of radiation processes.

[4] The solar radiation parameterization includes the absorption due to ozone, water vapor, oxygen, carbon dioxide, cloud and aerosols and the multiple-scattering due to clouds, aerosols and gases. The solar radiation processes are taken into account grouping all spectral regions with the same absorption coefficient: the $\mathrm{k}$ distribution approach [Chou, 1992; Chou and Lee, 1996]. The spectrum is divided into two regions. one including the spectral regions of ultraviolet and photosynthetically active radiation (PAR) (wavelength $\lambda<0.7 \mu \mathrm{m}$ ), and the other including the three thermal infrared bands (wavelength $\lambda \geq 0.7 \mu \mathrm{m}$ ). The ultraviolet and PAR band is further divided into eight subbands, with seven subbands in the ultraviolet spectrum and a subband in the PAR spectrum. For each seven subbands of ultraviolet spectrum an effective coefficient for ozone absorption and an effective cross section for Rayleigh scattering are determined. For the PAR subband an absorption coefficient of water vapor is also determined. Each band of the thermal infrared spectrum is divided into ten subbands, where the absorption of water vapor is treated using the $\mathrm{k}$ distribution method or the one-parameter temperature scaling for water vapor continuum absorption. The solar radiation fluxes are computed using the two-stream adding approximation for a composite of atmospheric layers, being the reflectivities and transmissivities of a cloud and of aerosol layer computed using the $\delta$-Eddington approxima- tion [Joseph et al., 1976]. The clouds are considered planeparallels. Three types of clouds are taken into account. low, middle and high clouds, in accordance with the height of the bottom and top of clouds. In the ultraviolet and PAR bands the spectral absorption of clouds is considered null, while for the thermal infrared bands the effects of absorption and scattering of clouds are taken into account.

[5] The thermal infrared radiation parameterization scheme takes into account the effects of the greenhouse gases (water vapor, $\mathrm{CO}_{2}, \mathrm{CH}_{4}, \mathrm{O}_{3}, \mathrm{~N}_{2} \mathrm{O}, \mathrm{CFC}_{11}, \mathrm{CFC}_{12}$, and $\mathrm{HCFC}_{22}$ ), clouds and aerosols; spectral emissivity of the surface and multiple-scattering due to atmospheric gases, clouds and aerosols. For longwave absorption, broadband transmission functions of water vapor [Chou, 1984], carbon dioxide [Chou and Peng, 1983] and ozone [Chou and Kouvaris, 1986] are used. The approach relies on parameterizations of diffusive transmittance functions appropriately weighted by the Planck blackbody source terms. The scheme includes the water vapor line and continuum absorption, carbon dioxide absorption through band centers and band wing regions, and infrared ozoneabsorption bands. The bands are determined through the $\mathrm{k}$ distribution method and the thermal spectrum is divided into ten spectral bands. The infrared radiative transfer model also computes the fluxes due to trace gases $\left(\mathrm{N}_{2} \mathrm{O}\right.$, $\mathrm{CH}_{4}, \mathrm{CFC}_{11}, \mathrm{CFC}_{12}, \mathrm{CFC}_{22}, \mathrm{HCFC}_{22}$, two minor $\mathrm{CO}_{2}$ bands), clouds and aerosols. Clouds are treated as blackbodies, except for high clouds which are considered as gray bodies. High cloud emissivity is assumed to be $50 \%$ of that from blackbody.

[6] We test the longwave radiation model using the original values of the absorption coefficients for the first $k$ distribution function due to the water vapor continuum

Table 1b. Equipment Used for Collecting Radiation Data During WETAMC/LBA Campaign (6 to 20 February) in the Pasture Sites

\begin{tabular}{|c|c|c|c|c|}
\hline Equipment & Measurement & Sensibility & Units & Models \\
\hline Pyronometer & $\begin{array}{l}\text { incident and reflected } \\
\text { shortwave radiation }\end{array}$ & $\begin{array}{l} \pm 2 \% \text { in } 293 \mathrm{~K} \text { and } \\
500 \mathrm{Wm}^{-2}\end{array}$ & $\mathrm{~W} \mathrm{~m}^{-2}$ & $\begin{array}{l}\text { Solarimeter CM21 Kipp and } \\
\text { Zonen (Delft, Netherlands) }\end{array}$ \\
\hline Sensor quantum & PAR & $\pm 5 \%$ & $\begin{array}{l}\mathrm{W} \mathrm{m}^{-2} \text { or } \\
\mu \mathrm{mol} \mathrm{m}^{-2} \mathrm{~s}^{-1}\end{array}$ & $\begin{array}{l}\text { Sensor quantum LI-190SA } \\
\text { Licor (Nebraska) }\end{array}$ \\
\hline Pyronometer $(\downarrow)(\uparrow)$ & net shortwave radiation & $\pm 2 \%$ & $\mathrm{~W} \mathrm{~m}^{-2}$ & $\begin{array}{l}\text { CG1 Kipp and Zonen (Delft, } \\
\text { Netherlands) }\end{array}$ \\
\hline Pyrgeometer $(\downarrow)(\uparrow)$ & $\begin{array}{l}\text { incoming longwave } \\
\text { radiation and longwave } \\
\text { radiation emmited by } \\
\text { the surface }\end{array}$ & $\pm 10 \%$ & $\mathrm{~W} \mathrm{~m}^{-2}$ & $\begin{array}{l}\text { CG1 Kipp and Zonen (Delft, } \\
\text { Netherlands) }\end{array}$ \\
\hline
\end{tabular}


Table 2. Values of the Cloud Optical Thickness Used in the Radiation Model

\begin{tabular}{lcc}
\hline \multicolumn{1}{c}{ Classification of Clouds } & Type & Optical Thickness \\
\hline Low & $\mathrm{Sc}$ & 8.0 \\
Middle & $\mathrm{Ac}$ & 7.0 \\
High & $\mathrm{Ci}$ & 5.0 \\
$\begin{array}{l}\text { Strong vertical development } \\
\quad \text { between low and middle levels }\end{array}$ & $\mathrm{Cb}$ & 5.5 \\
$\begin{array}{l}\text { Strong vertical development } \\
\quad \text { between low, middle and high levels }\end{array}$ & $\mathrm{Ns}$ & 21.0 \\
\hline
\end{tabular}

absorption for the third band. The results showed that there was a large overestimation of the simulated longwave counterradiation flux when compared to the observed data (standard deviation equal to $22.3 \%$ ). We also test the longwave radiation model using the original values of these absorption coefficients multiplied by 2 . We noted that there was an improvement of the simulation of the longwave counterradiation flux (standard deviation equal to $11.9 \%$ ). Thus, in the present study we use the doubled values of these coefficients instead of their original values. Detailed description of the radiation models are given by Chou and Suarez [1994, 1999].

\section{Data}

\subsection{LBA Data Sets}

[7] As mentioned earlier, the radiation models are tested for two contrasting vegetation regions. forest and grassland. We use radiation and radiosonde data from the LBA. The forest site was the Biological Reserve of Rio Jaru $\left(10^{\circ} 05^{\prime} \mathrm{S}\right.$, $61^{\circ} 55^{\prime} \mathrm{W}, 120 \mathrm{~m}$ above the sea level) which is a large area (268150 hectares) of intact tropical forest. The grassland was situated in the Fazenda Nossa Senhora Aparecida $\left(10^{\circ} 45^{\prime} \mathrm{S}\right.$, $62^{\circ} 22^{\prime} \mathrm{W}, 220 \mathrm{~m}$ above the sea level). This area, which is covered predominantly by grass (Brachiaria brizantha), was deforested about 15 years ago and is a typical ranchland for this region of Amazonia. In the case of the forest reserve, in the sector from northwest, clockwise to south-southeast, the fetch is undisturbed forest for several tens of kilometers. While the region where the grassland site is situated is characterized by areas with strips of pasture and forest side-by-side. These areas were created due to the deforestation management policy in the Rondonia region. Detailed descriptions of the sites are given by Culf et al. [1995] and Gash et al. [1996].

[8] In order to test the radiation model for the forest and grassland cases we use the radiation and radiosonde data collected during the WETAMC/LBA campaign from 6 to 20 February 1999, which corresponds to a wet period. The surface radiation fluxes computed using the radiation models are compared with the radiation data from the LBA. These data collected in the forest region correspond to the surface net radiation while in the grassland area they correspond to the irradiance, reflected solar radiation, photosynthetically active radiation (PAR), net radiation at the surface, longwave incoming radiation and longwave radiation emitted from the surface. The radiation data collected in the grassland region are the same as those in the forest region except for the net radiation at the surface. The data for both the forest and grassland sites correspond to an average over the last 30 minutes. The equipment used for collecting the data at the forest and pasture sites are indicated in Tables $1 \mathrm{a}$ and $1 \mathrm{~b}$, respectively. At the forest site the radiation fluxes measurements were made from the top of a $58.35 \mathrm{~m}$ high tower and the radiosonde launching occurred in a place situated $5 \mathrm{~km}$ far from the tower. At the pasture site the radiation data measurements were made at 5 $\mathrm{m}$ height and the radiosonde launching occurred near the surface station.

\subsection{Input Data for Running the Radiation Model}

[9] The radiation model is run using 76 pressure levels from the surface to $0.0001 \mathrm{hPa}$. The input data for the model are the radiosonde data from the LBA (6 to 20 February 1999). The vertical profiles of temperature and specific humidity are obtained from the radiosonde data for 56 model atmospheric levels, from the surface to $30 \mathrm{hPa}$. Above $30 \mathrm{hPa}$, data from the tropical standard atmosphere are used (AFGL-T 6-0110 NASA, http.//climate.gsfc.nasa. gov/ chou/Home.html).

[10] During the WETAMC/LBA campaign measurements were not made for spectral surface emissivity and reflectance. Also, there was no information about the type of clouds and their characteristics, aerosol and layer ozone concentration. As mentioned earlier, the recent version of Chou and Suarez's [1994] model treats the surface emissivity in 10 spectral bands in the infrared region. So, in order to run the model we use values of the spectral surface emissivity and reflectance for evergreen broadleaf trees and short grass for tropical forest and pasture, respectively. The data of the spectral surface emissivity are obtained from Wilber et al. [1999] and the spectral reflectance data are obtained from BATS (Biosphere-Atmosphere Transfer Scheme) [Dickinson et al., 1986]. The values of the spectral reflectance in the region of ultraviolet and photosynthetically active radiation $(\lambda<0.7 \mu \mathrm{m})$ and in the near-infrared region $(\lambda>0.7 \mu \mathrm{m})$ are, respectively, 0.04 and 0.2 (forest) and 0.1 and 0.3 (pasture).

[11] In the case of ozone concentration, we use the ozone mixing-ratio profile obtained from the tropical standard atmosphere [McClatchey et al., 1972]. The types of clouds are inferred from the radiosonde data. Firstly, we assume that there is cloud when the relative humidity is equal to or higher than $85 \%$. The classification of the type of cloud in a layer is made taking into account the height (or level) where this occurs. The distinction between low and high levels is given by the model levels 62 and 40, which correspond to $680 \mathrm{hPa}$ and $400 \mathrm{hPa}$, respectively. The cloud optical thickness data are obtained from the summer mean values for $10^{\circ} \mathrm{S}$ given by Hahn et al. [2001]. Table 2 shows the cloud optical thickness values used in the model. Since no information was available about the effective particle size, we use a default value of

Table 3. Values of the Aerosol Optical Properties Used in the Radiation Model

\begin{tabular}{lc}
\hline & Value \\
\hline Aerosol optical thickness & 0.050 \\
Asymmetry factor & 0.743 \\
Single-scattering albedo & 0.989 \\
\hline
\end{tabular}



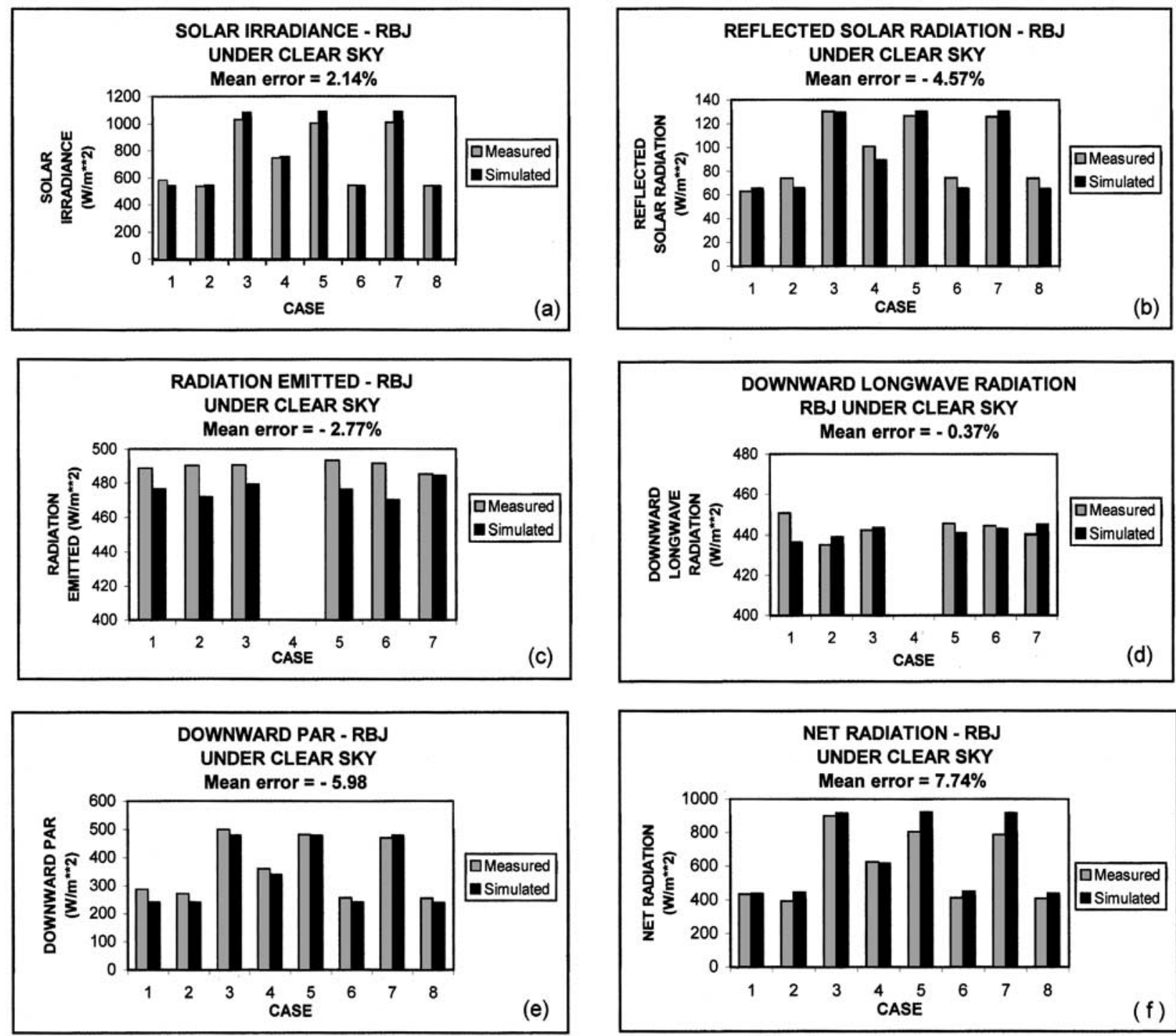

Figure 1. Comparisons between the radiation fluxes simulated by the model (black) and the observed data from LBA (gray) in the pasture site. Cases with clear sky condition.

$10 \mu \mathrm{m}$ for liquid water and $85 \mu \mathrm{m}$ for ice. The cloud amount is assumed as unity.

[12] The concentration of aerosol is higher during the dry period in the forest and pasture regions when the anthropogenic burning of savanna and forest occurs. Groundbased global Sun photometers at the sites of the AERONET global Sun photometer network [Holben et al., 1996] record small values of column aerosol optical depth during the wet period and elevation of its magnitude during the dry period. Considering the strong washout from precipitation of aerosol particles and the near absence of anthropogenic aerosols sources during the wet period, Tarasova et al. [2000] assumed that the smallest monthly mean value observed in June 1993 (dry season) is the maximum estimate for the wet period in Amazonia. Based on the above, and taking into account that there are no observed values of the aerosol optical thickness in the band of solar and thermal spectra, we use the values of aerosol optical properties given by
Chou [1992], which correspond to aerosols below $800 \mathrm{hPa}$ (Table 3).

\section{Results}

[13] In this section, the model radiation results are compared with observed data for the forest and grassland cases. In order to verify the model performance we use observed data of several days and for different times of a day for the two sites. We choose cases considering the situations of clear and cloudy sky conditions.

[14] Figures 1 and 2 show the simulated and observed values of the radiometric variables for clear and cloudy sky conditions, respectively, for the case of grassland. The model is run for 7 and 21 cases considering different days and times of a day for clear and cloudy sky conditions, respectively. As can be noted, there is a good agreement between the model simulations and the observations. The 

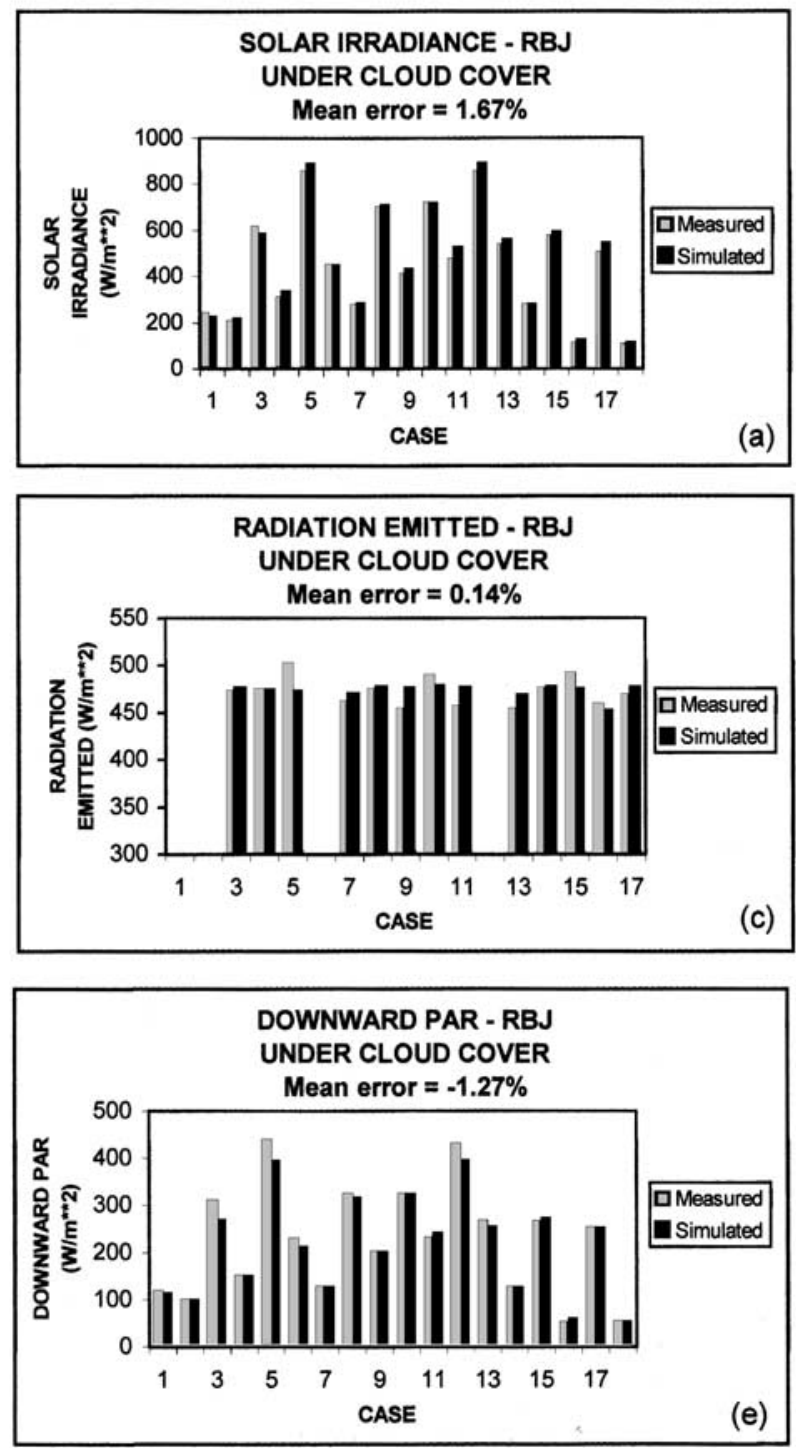
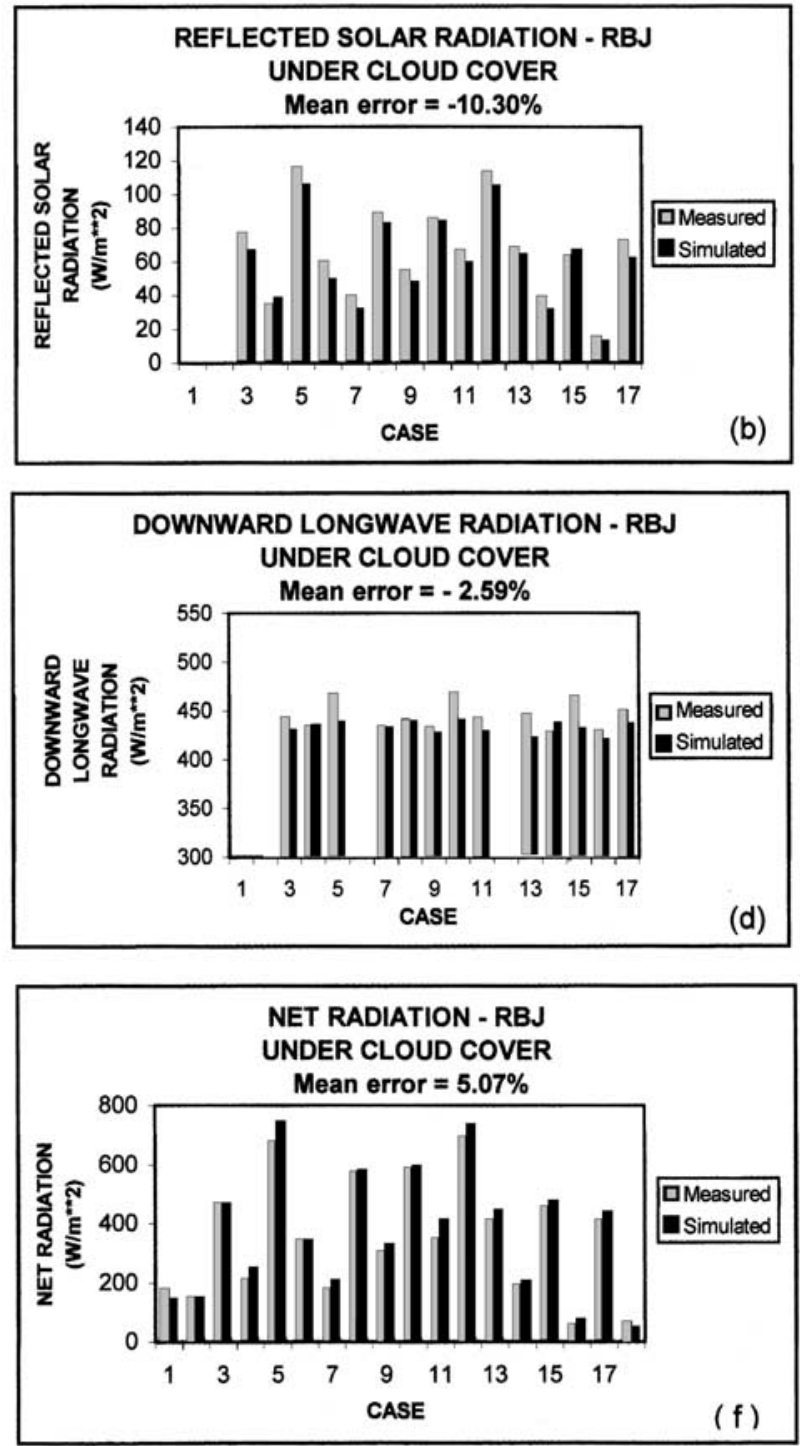

Figure 2. Same as Figure 1 but for the cases with cloudy sky condition.

mean errors for the irradiance, downward longwave radiation, and radiation emitted from the surface are lower than $3.1 \%$ and $1 \%$ for clear and cloudy sky conditions, respectively. The largest mean errors occur in the reflected solar radiation, being lower than $6 \%$ in both the cases. In general, the model simulations match better the observations for cloudy sky conditions. This may be due to the fact that the LBA data represent an average over $30 \mathrm{~min}$. Since there is a large daily variation of cloud cover in the Amazonian region, mainly during the wet season, the episodes of clear sky conditions occur in a time period less than $30 \mathrm{~min}$. This may affect the analysis of the model performance in the case of clear sky conditions. As it is note in Figures 1 and 2, for clear sky conditions the model results are slightly overestimated in relation to the observed values in the most cases, while for cloudy sky conditions there is no clear tendency of the results.

[15] The performance of the model for the forest region is verified considering 8 and 18 cases for clear and cloudy sky conditions. The simulated and observed values of the radio- metric variables for clear and cloudy sky conditions are shown in Figures 3 and 4, respectively. As in the case of grassland, in general there is a good agreement between the simulated and observed data. Again, the better results correspond to the simulations of the irradiance, downward longwave radiation, and radiation emitted from the surface whose mean errors are lower than 3\% for both clear and cloudy sky conditions, and the largest mean errors occurs in the simulation of the reflected solar radiation, being lower than $10.5 \%$ in both the cases. In general, the model simulations match better the observations for cloudy sky conditions, as in the case of grassland. From Figures 3 and 4 , it can be noted that the differences between the model simulations and observed data are lower in the case of pasture compared to the forest. This is due to fact that the radiosonde launching occurred at $5 \mathrm{~m}$ away from the surface station in the pasture site while in the forest site it occurred at $5 \mathrm{~km}$ away from the tower. Since both data obtained from the surface station (and tower) and radiosonde data are used for running the model, higher differences may be expected 

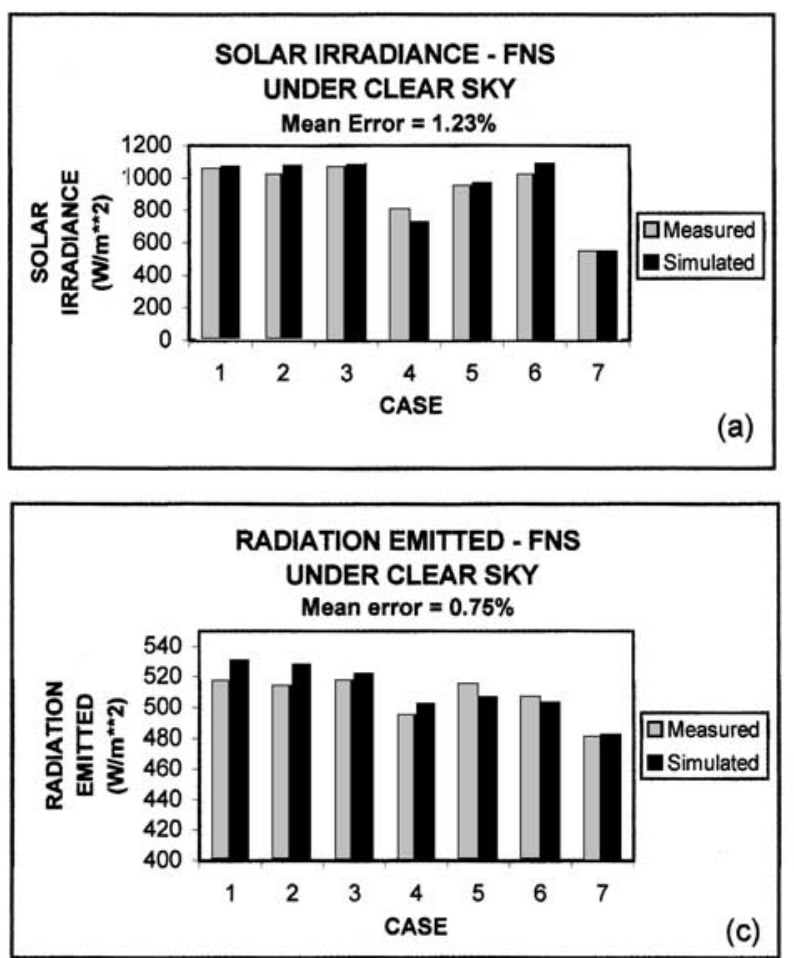
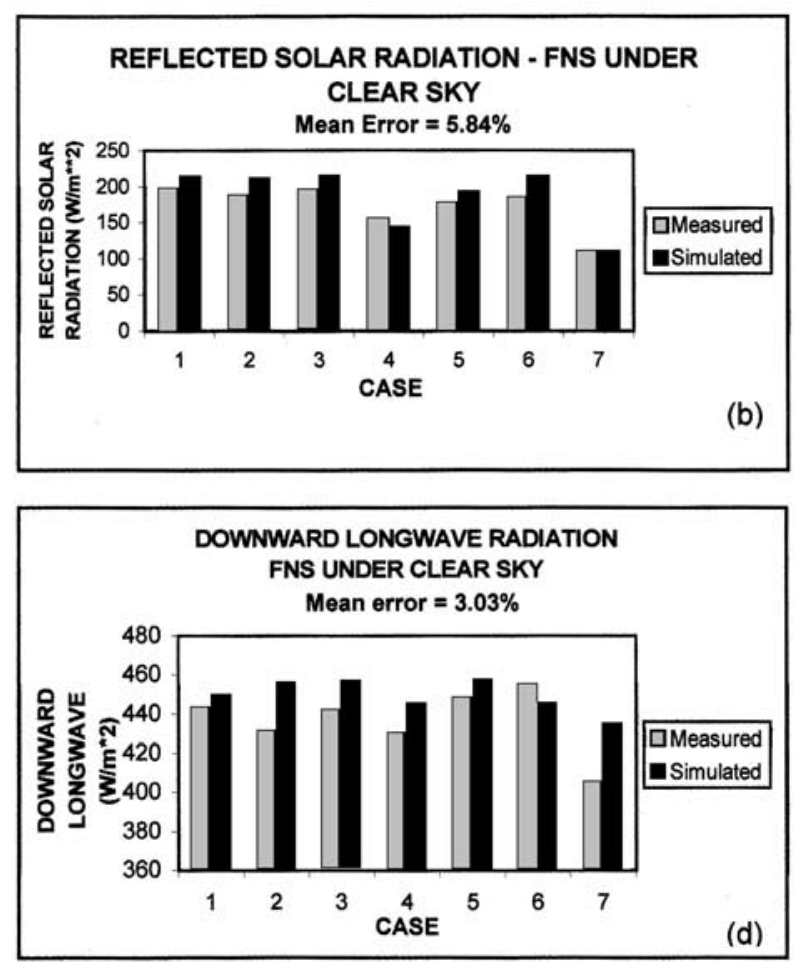

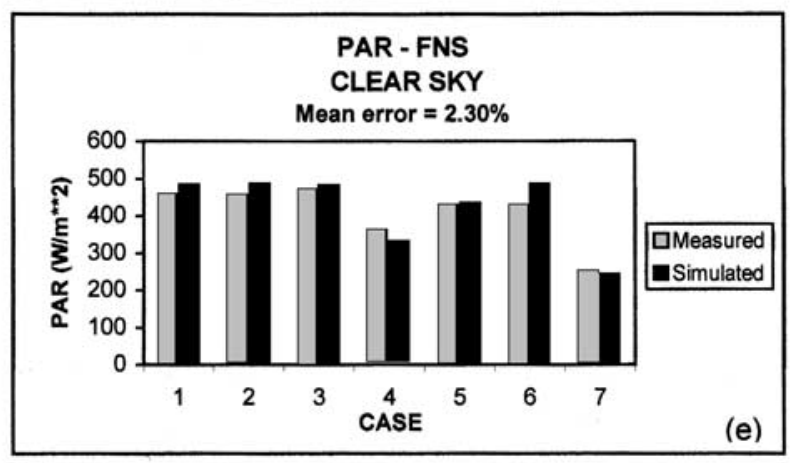

Figure 3. Same as Figure 1 but for the forest site.

in the forest case. However, in both cases the model simulations are in general in good agreement with the observations, with the mean errors being around the same order or lower than the instrument errors, except in the case of the reflected solar radiation (see Tables 1a and 1b). Since there is no information about the land surface albedo we use the values given in BATS for evergreen broadleaf trees and short grass for forest and grassland, respectively. The use of the actual values of the spectral surface reflectance may improve the model simulations of the reflected solar radiation and, consequently, the net radiation at the surface.

[16] In order to verify if the results are statistically significant we calculated the correlation coefficient (CC) between the model simulations and observed data. In calculating the $\mathrm{CC}$ we consider separately the simulations for clear and cloudy skies for both the forest and pasture. We calculated also the $\mathrm{CC}$ taking into account all the simulated values (clear sky plus cloudy sky) for each site. Finally, we use all the model simulations for the two sites (forest plus pasture). The CCs between the model simula- tions and observations are shown in Table 4 . We use the two side t-test to verify the significance of the correlations. From Table 4 it can be seen that in the case of the forest the simulated fluxes are strongly correlated with the observations $(\mathrm{CC}>0.98)$, significant at $99 \%$ confidence level, except in the case of the longwave radiation. This may be related to the fact that the radiosonde launching occurred 5 $\mathrm{km}$ from the tower, where the radiation fluxes were measured. In the case of the pasture, the CC are significant at $99 \%$ level for all the radiation fluxes, except the downward longwave radiation for clear sky conditions. For cloudy sky and all sky, the radiation fluxes are strongly correlated with the observed data, except the downward longwave radiation. When all the simulations for both the sites are taken into account together, the CC are significant at $99 \%$ level for all the radiation fluxes, except the downward longwave radiation.

[17] We also used the Bonferrone technique for the statistical analyses of the model results. The Bonferrone procedure consists in obtaining the best fit regression line 

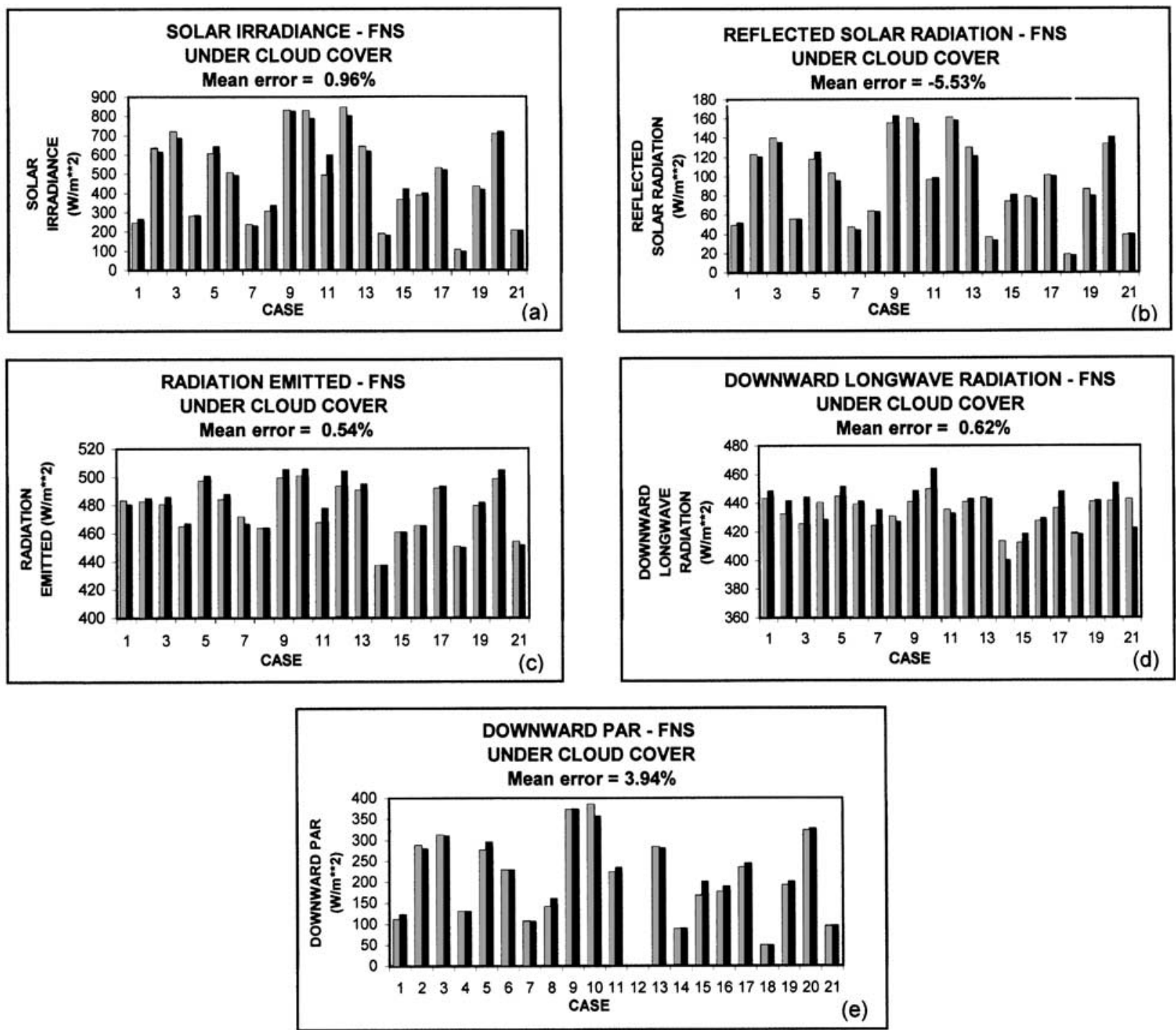

Figure 4. Same as Figure 2 but for the forest site.

and it is useful for calculating the regressions parameters when the number of estimates and observed data is not too large. The best fit occurs when the slope $\beta_{1}$ is close to 1 and/ or the intercept $\beta_{\mathrm{o}}$ is close to zero, indicating that the estimates approximate to the observed data. Details about this method are given by Neter and Wasserman [1974]. We use the Bonferrone method taking into account all the estimates for clear and cloudy skies (all skies) in both the cases of forest and grassland. The fits to be presented in the next figures are made for a $95 \%$ confidence interval. In these figures the coefficient of determination (the square of the correlation coefficient) is also shown.

[18] The fits for the solar irradiance, reflected solar radiation, longwave radiation emitted from the surface, downward longwave radiation, downward PAR and net radiation for the forest are shown in Figures $5 \mathrm{a}-5 \mathrm{f}$, respec-

Table 4. Correlation Coefficients Between the Simulated Fluxes and the Observed Data From LBA

\begin{tabular}{|c|c|c|c|c|c|c|c|c|c|}
\hline & \multicolumn{3}{|c|}{ Forest } & \multicolumn{3}{|c|}{ Pasture } & \multicolumn{3}{|c|}{ Forest and Pasture } \\
\hline & Clear Sky & Cloudy Sky & All Sky & Clear Sky & Cloudy Sky & All Sky & Clear Sky & Cloudy Sky & All Sky \\
\hline Solar irradiance & $0.9973^{\mathrm{a}}$ & $0.9970^{\mathrm{a}}$ & $0.9965^{\mathrm{a}}$ & $0.9838^{\mathrm{a}}$ & $0.9892^{\mathrm{a}}$ & $0.9923^{\mathrm{a}}$ & $0.9910^{\mathrm{a}}$ & $0.9925^{\mathrm{a}}$ & $0.9937^{\mathrm{a}}$ \\
\hline Reflected solar radiation & $0.9833^{\mathrm{a}}$ & $0.9889^{\mathrm{a}}$ & $0.9876^{\mathrm{a}}$ & $0.9683^{\mathrm{a}}$ & $0.9936^{\mathrm{a}}$ & $0.9892^{\mathrm{a}}$ & $0.9897^{\mathrm{a}}$ & $0.9919^{\mathrm{a}}$ & $0.9897^{\mathrm{a}}$ \\
\hline Downward par & $0.9930^{\mathrm{a}}$ & $0.9941^{\mathrm{a}}$ & $0.9925^{\mathrm{a}}$ & $0.9710^{\mathrm{a}}$ & $0.9925^{\mathrm{a}}$ & $0.9914^{\mathrm{a}}$ & $0.9802^{\mathrm{a}}$ & $0.9914^{\mathrm{a}}$ & $0.9890^{\mathrm{a}}$ \\
\hline Net radiation at the surface & $0.9810^{\mathrm{a}}$ & $0.9944^{\mathrm{a}}$ & $0.9923^{\mathrm{a}}$ & & & & $0.9810^{\mathrm{a}}$ & $0.9944^{\mathrm{a}}$ & $0.9923^{\mathrm{a}}$ \\
\hline Longwave emitted from the surface & -0.6767 & 0.3650 & 0.4155 & $0.8910^{\mathrm{a}}$ & $0.9857^{\mathrm{a}}$ & $0.9793^{\mathrm{a}}$ & $0.8880^{\mathrm{a}}$ & $0.8492^{\mathrm{a}}$ & $0.8634^{\mathrm{a}}$ \\
\hline Downward longwave radiation & -0.3851 & 0.4114 & 0.2500 & 0.6461 & $0.7605^{\mathrm{a}}$ & $0.6521^{\mathrm{a}}$ & 0.2881 & $0.4721^{\mathrm{a}}$ & $0.4157^{\mathrm{a}}$ \\
\hline
\end{tabular}

${ }^{\text {a }}$ Correlation coefficients are significant at $99 \%$ confidence level. 

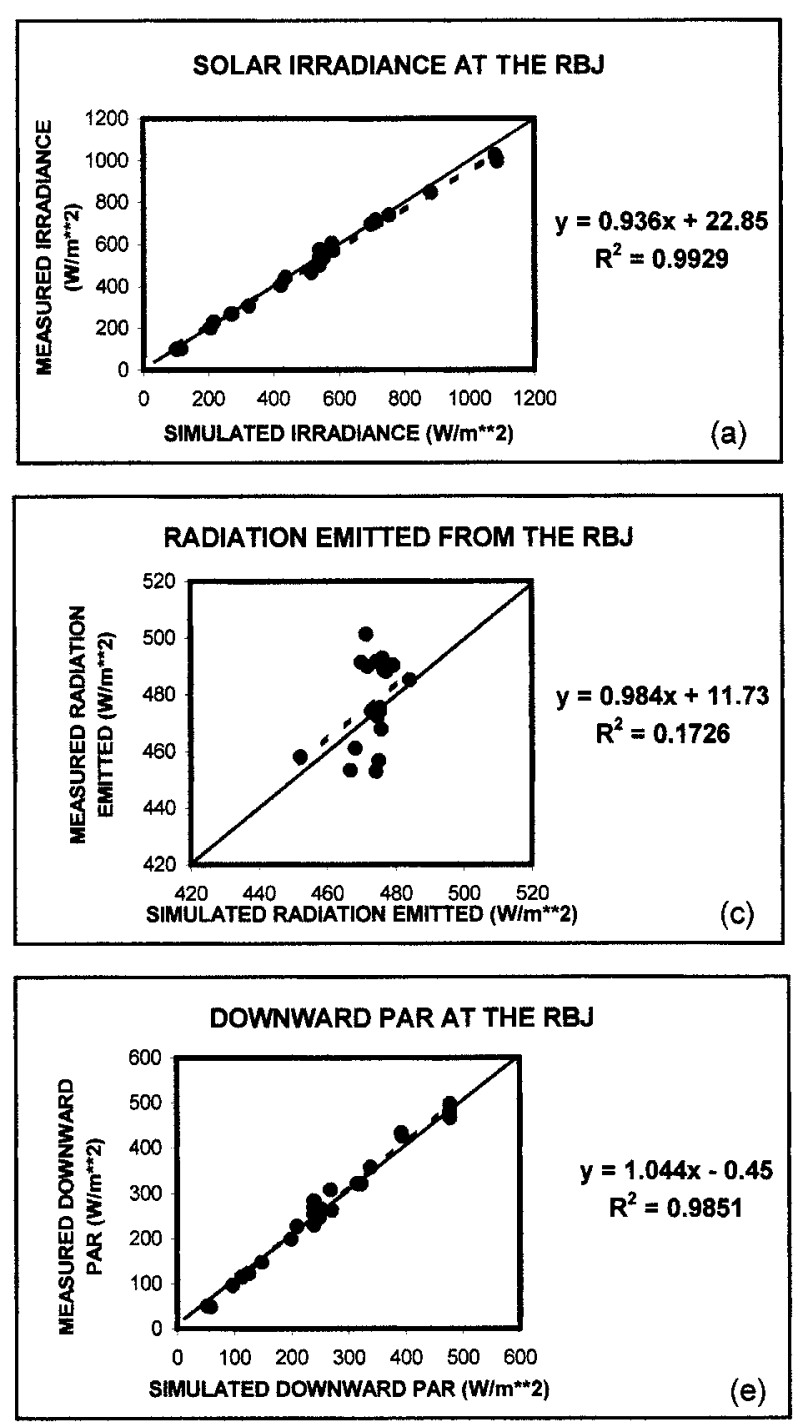
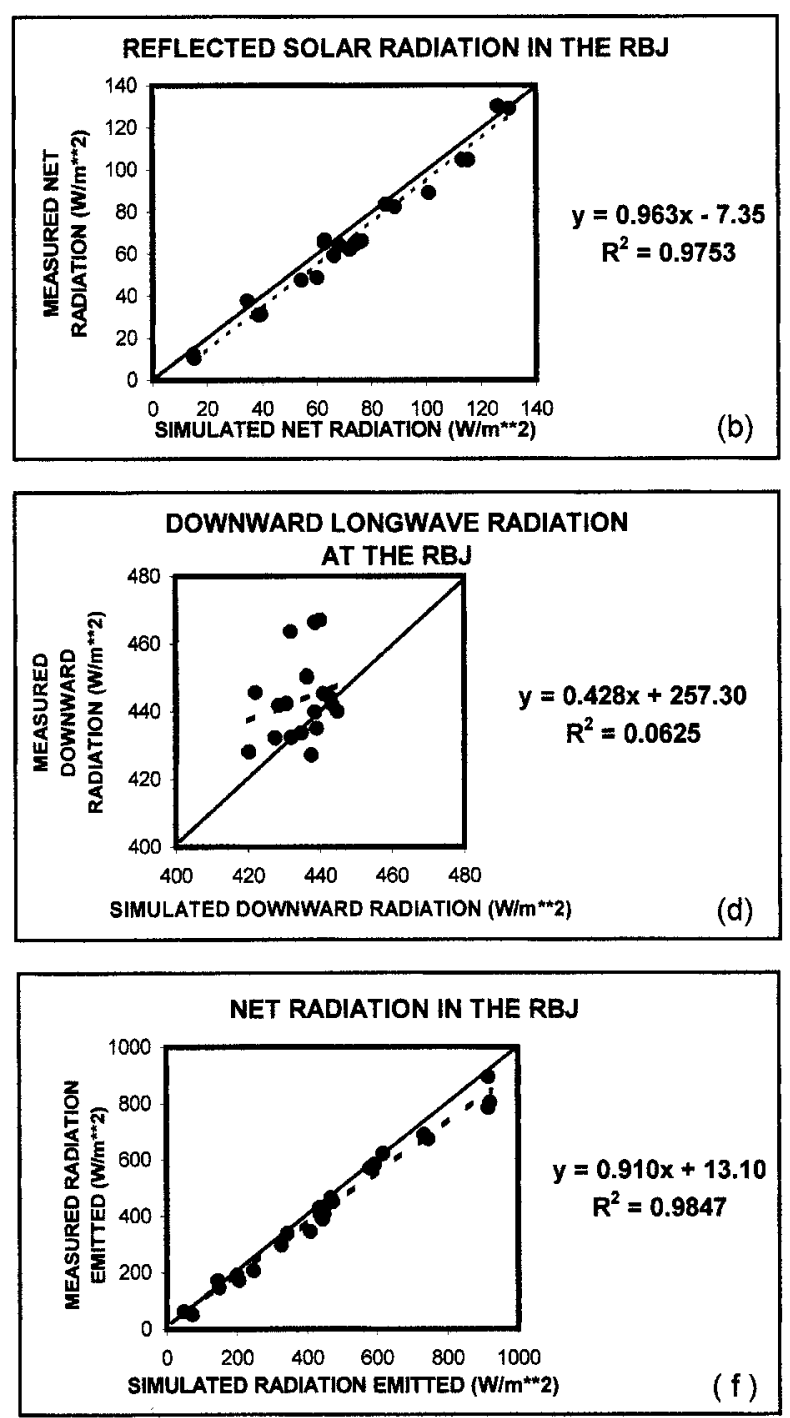

Figure 5. Radiation fluxes of (a) solar irradiance, (b) reflected solar radiation, (c) longwave radiation emitted from the surface, (d) downward longwave radiation, (e) downward PAR, and (f) net radiation at the surface, for all sky conditions in the forest site. Shown are the ground true values of the fluxes (circles), the line where the simulated values are equal to the observed data (solid line) and the best fits for the simulations given by the Bonferrone method (dashed line). The linear regression equation and the coefficient of determination $\left(\mathrm{R}^{2}\right)$ are also shown. Units are $\mathrm{W} \mathrm{m}{ }^{-2}$.

tively. As can be seen, the estimates fit well the observed data except for the longwave radiation. The best fits correspond to the solar irradiance, reflected solar radiation, downward PAR and net radiation. In these cases the criterion of Bonferrone is satisfied and the coefficient of determination is higher than 0.97. In the case of pasture (Figures 6a-6e), the simulated values fit well the observations in the case of the solar irradiance, reflected solar radiation, downward PAR and longwave radiation emitted from the surface. The CCs are higher than 0.97. In the case of the downward longwave radiation, $\mathrm{CC}$ is low and the Bonferrone criterion is not satisfied because the scatter of the downward radiation values does not clearly show a linear behavior. Thus, the error is large in this case, for a linear fit. We use the Bonferrone technique considering all the simulated cases (all sky and forest plus pasture). The results are similar to the case of pasture (Figures $7 \mathrm{a}-7 \mathrm{e}$ ). In general, the use of the Bonferrone method confirms the information given by the calculation of the $\mathrm{CC}$.

\section{Conclusions}

[19] The present paper showed the feasibility of the Chou and Suarez's [1994, 1999] radiation models for computing the radiation balance at the surface in the areas of grassland and forest in the Amazonian region.

[20] In order to run and test the model against the observations we used radiation and radiosonde data collected at these two sites during the WETAMC/LBA campaign (6 to 20 February 1999), which corresponds to a wet 

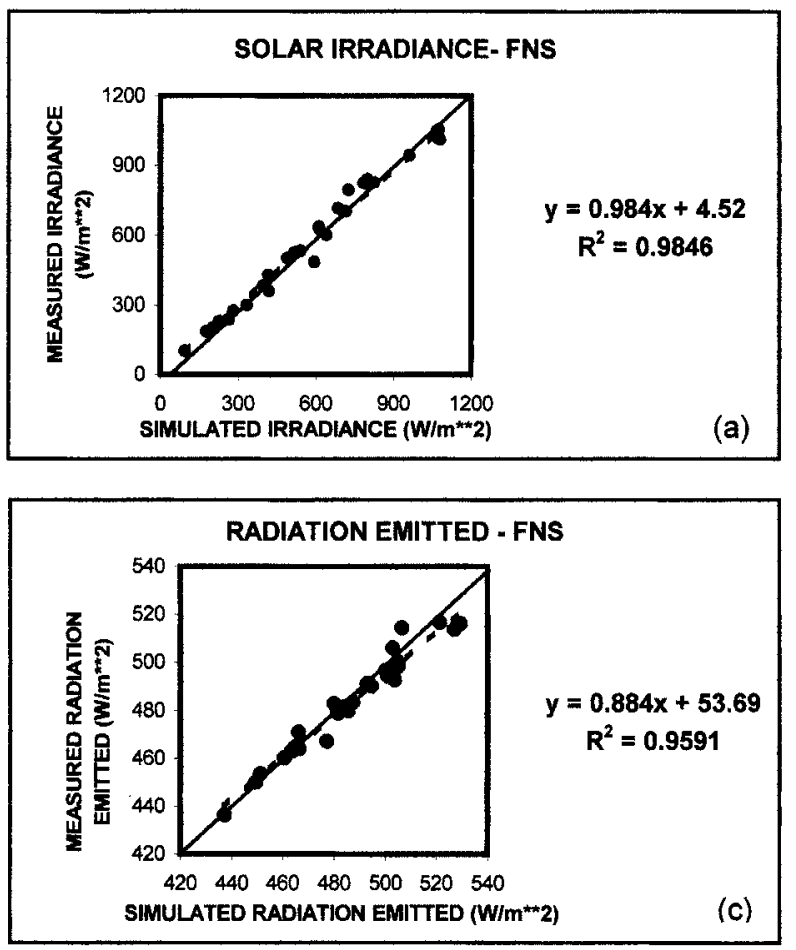
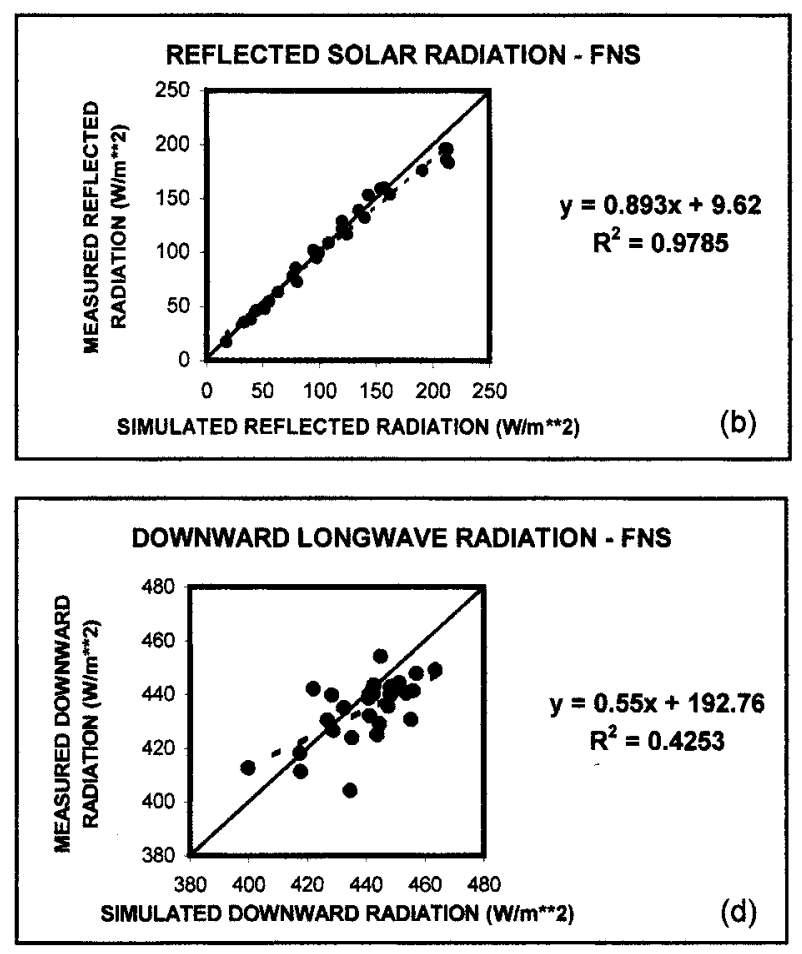

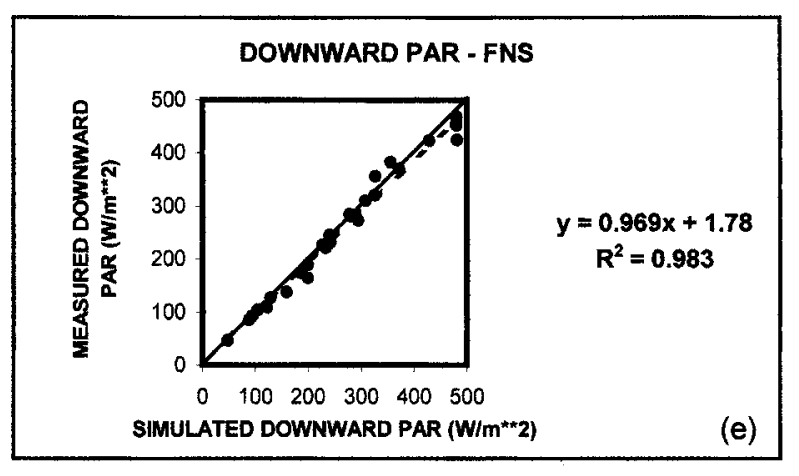

Figure 6. Radiation fluxes of (a) solar irradiance, (b) reflected solar radiation, (c) longwave radiation emitted from the surface, (d) downward longwave radiation, and (e) downward PAR for all sky conditions in the pasture site. Legend is similar to that in Figure 5.

period in Amazonia. In this campaign measurements were not made for surface emissivity and reflectance. Also, information of clouds, aerosols and ozone are not available to run the model. So, we made some assumptions. We use the values of the spectral surface emissivity and reflectance of evergreen broadleaf trees and short grass for the tropical forest and grassland, respectively. The type of clouds was inferred from the radiosonde profile taking into account the height where the relative humidity was equal to or higher than $85 \%$, and the cloud optical thickness were those from the summer mean values for $10^{\circ} \mathrm{S}$. The ozone mixing-ratio was obtained from the tropical standard atmosphere. Since the values of column aerosol optical depth are small in the wet period we used the values of the aerosol optical properties given by Chou [1992].

[21] For verifying the model performance the model was run using observed data of several days and for different times of day for the two sites. Clear and cloudy skies conditions were taken into account. The results showed that in general the simulations and observed data are in good agreement for both the cases of forest and grassland. The mean errors are around same order or lower than the instrument errors, except in the case of the reflected solar radiation. The lower mean errors $(<3 \%)$ correspond to the solar irradiance, downward longwave radiation and longwave emitted from the surface for both clear and cloudy skies. The largest mean errors occur in the simulation of the reflected solar radiation $(<6 \%$ for the pasture and $<10.5 \%$ for the forest). This may be due to the use of spectral surface reflectance of evergreen broadleaf trees and short grass for tropical forest and pasture, respectively. The use of actual values of the land surface albedo may improve the model simulation. Although the model results are in good agreement with the observations in both the sites, the simulated values match better the observations in the pasture relative to the forest. This may due to the fact that the radiosonde 

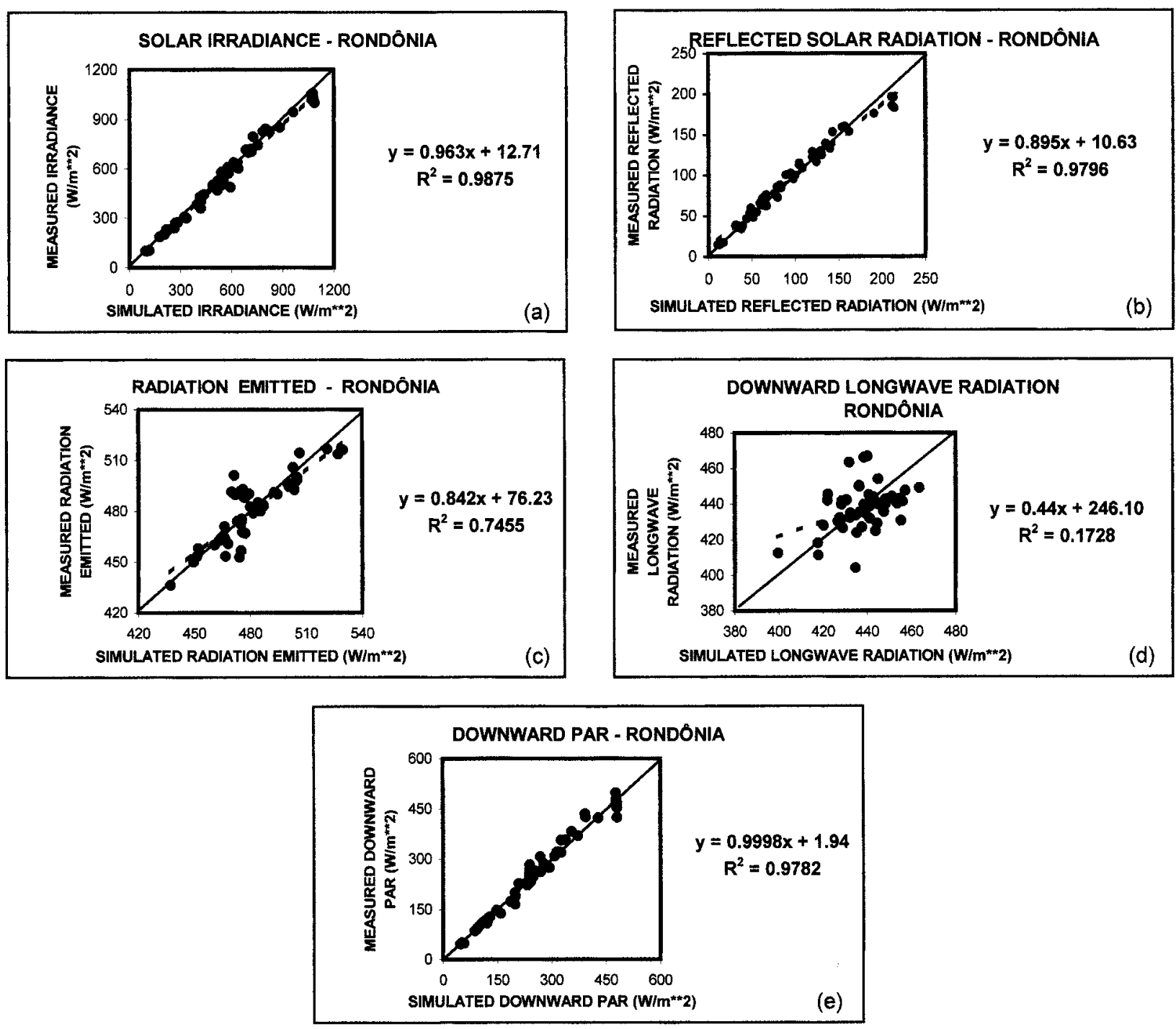

Figure 7. Same as Figure 6 but for all sky conditions in the pasture and forest sites. Legend is similar to that in Figure 5.

launching occurred at $5 \mathrm{~m}$ away from the surface station in the pasture site while in the forest site it occurred at $5 \mathrm{~km}$ away from the tower.

[22] In order to verify if the model results are statistically significant we calculated the correlation coefficient (CC) between the model simulations and observed data and used the Bonferrone technique. The results showed that in general the simulated fluxes are strongly correlated with the observed data $(\mathrm{CC}>0.97)$ significant at $99 \%$ confidence level, except in the case of the downward longwave radiation. The use of the Bonferrone method confirmed the information given by the $\mathrm{CC}$ calculation.

[23] The present study showed the feasibility of applying Chou and Suarez models to the calculations of surface radiation fluxes for forest and pasture scenarios in Amazonia. Although some assumptions were made due to the lack of information about some input data, the results were in good agreement with the observations.
[24] Acknowledgments. We are thankful to Ming-Dah Chou from the Goddard Space Flight Center, NASA, for providing the solar radiation and longwave radiation models. Thanks are due to all the participants involved with the LBA project, supported by FAFESP (Funcação de Amparo à Pesquisa do Estado de São Paulo), grant 1997/9926-9 (M. A. F. da Silva Dias, coordinator). Thanks are also due to R. G. Moura (CPTEC), C. Von Randow (CPTEC) and A. O. Manzi for providing the radiation data and to G. F. Fisch (CTA) for providing the radiosonde data. Thanks are also owed to T. A. Tarasova for the helpful discussions.

\section{References}

Chou, M.-D., Broadband water vapor transmission functions for atmospheric IR flux computations, J. Atmos. Sci., 41, 1775-1778, 1984.

Chou, M.-D., A solar radiation model for use in climate studies, J. Atmos. Sci., 49, 762-772, 1992.

Chou, M.-D., and L. Kouvaris, Monochromatic calculations of atmospheric radiative transfer due to molecular line absorption, J. Geophys. Res., 91, 4047-4055, 1986.

Chou, M.-D., and K.-T. Lee, Parameterizations of the absorption of solar radiation by water vapor and ozone, J. Atmos. Sci., 53, 1203-1208, 1996. 
Chou, M.-D., and L. Peng, A parameterization of the absorption in the 15 $\mu \mathrm{m} \mathrm{CO}_{2}$ spectral region with application to climate sensitivity studies, J. Atmos. Sci., 40, 2183-2192, 1983.

Chou, M.-D., and M. J. Suarez, An efficient thermal infrared radiation parameterization for use in general circulation models, Technical Report Series on Global Modeling and Data Assimilation, Tech. Memo. 104606, vol. 3, 102 pp., Goddard Space Flight Center, Greenbelt, Md., 1994.

Chou, M.-D., and M. J. Suarez, A solar radiation parameterization (CLIRAD-SW) developed at Goddard Climate and Radiation Branch for Atmospheric Studies, Goddard Space Flight Center, Greenbelt, NASA Tech. Memo., NASA/TM-1999-104606(15), 1999.

Chou, M.-D., and W. Zhao, Estimation and model validation of surface solar radiation and cloud radiative forcing using TOGA COARE measurements, J. Clim., 10, 610-619, 1997.

Chou, M.-D., D. P. Kratz, and W. Ridgway, Infrared radiation parameterizations in numerical climate models, J. Clim., 4, 424-437, 1991.

Chou, M.-D., N. Ridgway, and M.-H. Yan, Parameterizations for water vapor IR radiative transfer in both the middle and lower atmospheres, J. Atmos. Sci., 52, 1159-1167, 1995.

Culf, A. D., G. Fisch, and M. G. Hodnett, The albedo of Amazonian forest and Ranchland, J. Clim., 8, 1544-1554, 1995.

Dickinson, R. E., A. Henderson-Sellers, P. J. Kennedy, and M. F. Wilson, Biosphere-Atmosphere Transfer Scheme for the NCAR Community Climate Model, Tech. Note 275+STR, 69 pp., Natl. Cent. for Atmos., Boulder, Colo., 1986.

Gash, J. H. C., C. A. Nobre, J. M. Roberts, and R. L. Victoria, An overview of ABRACOS, in Amazonian Deforestation and Climate, edited by J. H. C. Gash et al., pp. 1-14, John Wiley, New York, 1996.

Hahn, C. J., W. B. Rossow, and S. G. Warren, ISCCP Cloud properties associated with standard cloud types identified in individual surface observation, J. Clim., 14, 11-28, 2001.

Holben, B. N., A. Setzer, T. F. Eck, A. Pereira, and I. Slutsker, Effect of dry-season biomass burning on Amazon basin aerosol concentrations and optical properties, 1992-1994, J. Geophys. Res., 101, 19,465-19,481, 1996.

Joseph, J. H., W. J. Wiscombe, and J. A. Weinman, The delta-Eddington approximation for radiative flux transfer, J. Atmos. Sci., 33, 2452-2459, 1976.

McClatchey, R. A., R. W. Fenn, J. E. A. Selby, F. E. Voltz, and J. S. Garing, Optical properties of the atmosphere, Tech. Rep. AFCRL-72-0497, 108 pp., Air Force Cambridge Res. Lab., Bedford, Mass., 1972.

Neter, J., and W. Wasserman, Applied linear statistical models, 842 pp., R. D. Irwin, Homewood, Ill., 1974.

Tarasova, A. T., C. A. Nobre, T. F. Eck, and B. N. Holben, Modeling of gaseous, aerosol, and cloudiness effects on surface solar irradiance measured in Brazil's Amazonia 1992-1995, J. Geophys. Res., 105, 26,96126,969, 2000.

Wilber, A. C., D. P. Kratz, and S. K. Gupta, Surface emissivity maps for use in satellite retrieval of longwave radiation, NASA/TP-1999-209382, 35 pp., NASA, Washington, D. C., 1999.

S. H. Franchito, E. C. Moraes, and V. B. Rao, Centro de Previsão de Tempo e Estudos Climáticos (CPTEC), Instituto Nacional de Pesquisas Espaciais (INPE), CP 515, 12201-970 São José dos Campos, SP, Brazil. (fran@cptec.inpe.br) 